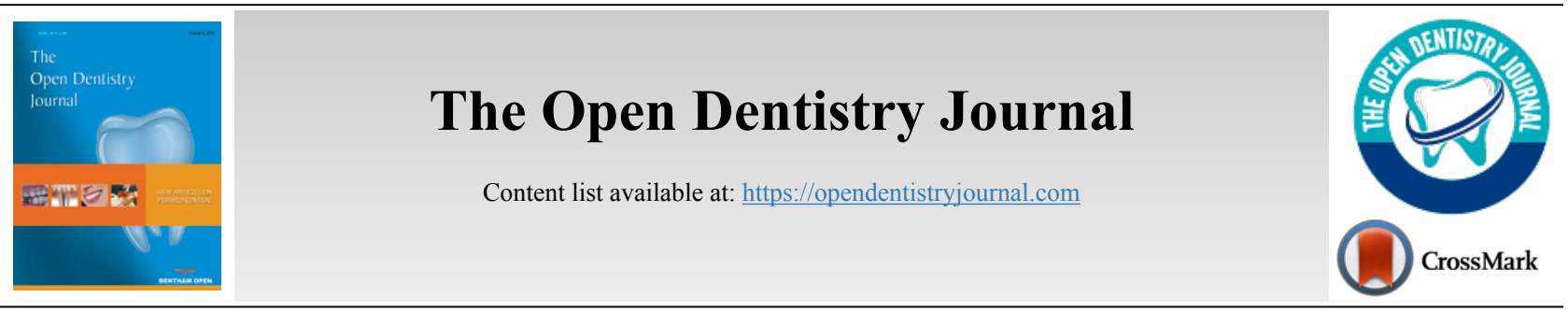

RESEARCH ARTICLE

\title{
Awareness of Oral Cancer Among Dental Patients in Mecca, Saudi Arabia
}

Mashael Alqahtani, ${ }^{1, *}$, Alla Nahhas ${ }^{2}$, Lujain Malibari ${ }^{2}$, Maryam Alghamdi², Sara Bazuhier ${ }^{2}$, Somaya Abdulrahman ${ }^{2}$, Khalid Aboalshamat ${ }^{3,4}$ and Rabab Salama ${ }^{3}$

${ }^{\prime}$ Department of Oral and Maxillofacial Pathology, Faculty of Dentistry, Umm Al-Qura University, Mecca, Saudi Arabia

${ }^{2}$ Department of Dentistry, Faculty of Dentistry, Umm Al-Qura University, Mecca, Saudi Arabia

${ }^{3}$ Department of Preventive Dentistry, Dental Public Health Division, Faculty of Dentistry, Umm Al-Qura University, Mecca, Saudi

${ }^{4}$ Medicine and Medical Science Research Center, Deanship of Scientific Research, Umm Al-Qura University, Mecca, Saudi Arabia

\begin{abstract}
:
Background:

Oral Cancer (OC) is a serious health problem affecting the oral cavity, which may lead to death. Alcohol, tobacco, and chewing betel are the main risk factors. Early diagnosis and adequate knowledge of OC may improve the survival rate.

Objective:

This study aimed to assess the knowledge about oral cancer among dental patients in Mecca.

Methods:

A cross-sectional study was conducted in the dental clinics of Mecca. Interviewer-administered questionnaires were distributed to 416 respondents aged 18 or older, who spoke Arabic or English, had no history of OC, and participated voluntarily. The questionnaire consisted of three sections. The first regarded demographical data, the second measured knowledge about OC, and the third was concerned with education regarding OC provided by health-care providers. The interviewers also educated the participants by handing brochures with information about OC.

Results:

Knowledge about OC among dental patients in Mecca was found to be significantly low. Only 102 of the 416 participants (24.5\%) had any knowledge. Only $3.4 \%$ of all participants had been educated about OC by their health-care providers.

Conclusion:

The results of this study show a considerable lack of general knowledge about OC among dental patients in Mecca. Health programs should be developed to raise the community's awareness.
\end{abstract}

Keywords: Knowledge, Awareness, Oral cancer, Dental patients, Mecca, Saudi Arabia.

\begin{tabular}{|l|l|l|l|}
\hline Article History & Received: March 16, 2020 & Revised: May 21, 2020 & Accepted: May 31, 2020
\end{tabular}

\section{INTRODUCTION}

Oral Cancer (OC) is the cancer that affects the lips, the floor of the mouth, the lining of the cheeks, the gums, the tongue, or the palate [1]. It is the sixth most common cancerrelated cause of death worldwide [2], with an estimated 657,000 new cases of oral and pharyngeal cancer and more than 330,000 deaths each year [3]. Squamous cell carcinomas account for more than $90 \%$ of OCs [4].

\footnotetext{
* Address correspondence to this author at the Department of Oral and Maxillofacial Pathology, College of Dentistry, Umm Al-Qura University, Mecca, Saudi Arabia; Tel: +966565666945; E-mail: Msqahtani@uqu.edu.sa
}

The main risk factors for $\mathrm{OC}$ are alcohol, tobacco consumption and chewing betel. A combination of these factors significantly increases the risk [5 - 7]. Other factors include human immunodeficiency virus (HIV), human papillomavirus (HPV), Candida infections, an unhealthy diet with low fruit and vegetable intake [8], and use of mouthwash containing alcohol [9]. OC mostly affects people older than 40 years [10] and low socioeconomic groups and is more prevalent in males than in females [11].

Patients who have received successful treatment for OC may have complications such as disfigurements and difficulty 
eating, swallowing, or speaking [12], which may significantly affect their quality of life [13]. Early diagnosis can improve the patient survival rate $[14,15]$. However, about $30 \%$ of patients wait more than three months before consulting a physician about signs of OC [16].

The general knowledge of OC has been evaluated among dental patients in many countries, revealing significant differences. Low levels have been observed in Iran and the UK $[17,18]$. Low rates have also been reported in the USA [19], whereas in Australia, more people appear to be aware of OC [12]. A study assessing the awareness levels among patients who are more likely to develop oral potentially malignant disorders and OC reported significant differences between genders, age groups, education and income levels, and types of tobacco as cigarettes or smokeless tobacco [20]. Similar studies have also been conducted in the Middle East. Two studies in Jordan found low levels of awareness, especially in high-risk patients of low socioeconomic levels [21, 22]. Similar results have been reported in Kuwait [23]. A recent study in Sudan revealed that most participants drew their knowledge of risk factors more from the media more than health workers [24].

Saudi Arabia includes many nationalities with certain social habits. Therefore, in the next few years, the prevalence of OC may increase significantly $[25,26]$. Only two studies have investigated the levels of awareness of OC, both conducted in Riyadh, the capital city. One study found that only $62.4 \%$ of dental patients were aware of OC and those with lower than tertiary education were significantly less aware [27]. Another study reported that half of the population had only heard of OC. Alcohol and tobacco consumption were identified as major risk factors by $81.7 \%$ of participants, and $56.3 \%$ of the participants with education lower than high school had less knowledge of the risk factors and signs of OC [28]. As studies have been conducted only in Riyadh, this study aimed to assess the awareness of OC among dental patients in Mecca.

\section{MATERIALS AND METHODS}

This was a cross-sectional survey conducted via a questionnaire. Participants were recruited from randomly selected dental clinics in Mecca according to availability, including a government hospital that is free for patients (Dental Teaching Hospital of Umm Al-Qura University) and private clinics (Quality Dental Clinic, Al-Bader Dental Clinic, Dr. Fahad Al-Zahrani Dental Clinic, Al-Motahedon Dental Clinic, Al-Bandar Dental Clinic, Al-Kakieya Dental Clinic, and Almadar Dental Clinic). Dental patients aged over 18 years with no history of OC and spoke Arabic or English were included in the study. Patients who did not agree to participate were excluded. The study questionnaire was an interview administered in English with Arabic translation. A researcher read the questions to each participant and explained any point that they did not understand. All respondents participated voluntarily and signed informed consent forms. The study was approved by the Institutional Review Board of the Faculty of Dentistry of Umm Al-Qura University (No. 113-18).

Considering an $\alpha$ value of 0.05 and $95 \%$ power, the sample size was estimated to be 385 . However, to account for possible attrition, 430 patients were approached. A convenience sample was used because some clinics did not allow us to administer the questionnaire in their premises.

The questionnaire was a modified version of a questionnaire used in a previous study in the USA [19] and consisted of three sections with closed-ended questions. The first section concerned demographic data (age, gender, education level, medical history, family history, exposure to the sun at the workplace, income, and current and previous alcohol and tobacco-related habits). The second section measured knowledge of OC by asking the patients whether they had heard of OC and its contagiosity and treatability, risk factors (smoking, smokeless tobacco, alcohol, spicy food consumption, dietary deficiencies or imbalance, poor oral hygiene, HPV infection, and exposure to the sun), signs and symptoms (specific clinical signs such as white or red patches in the mouth, difficulty chewing or swallowing, an abnormal lump in the mouth, and a sore that does not heal), and methods to lower the risk of OC. The third section queried patients regarding whether their health-care provider had educated them about OC. The questions in the first and third sections were answered by all participants, while those in the second section were only answered by participants who had heard of OC. The estimated time for completion of the questionnaire was 3-5 minutes.

A pilot study was conducted by administering the questionnaire to a random sample of 20 participants. Modifications were subsequently made based on their feedback to ensure the validity of the questionnaire. Data were collected, tabulated, and analyzed using the t-test, the chi-square test, ANOVA, the Mann-Whitney test, Fisher's exact test and the Kruskal-Wallis test. The analyses were performed using IBMSPSS Statistics version 23. A $P$ value of 0.05 was considered statistically significant.

Upon completion of the questionnaire, the participants were educated by means of brochures containing the most important information in the literature about OC, including its definition, prevalence, causes, early signs and symptoms, prevention, and self-examination [2, 18, 29]. The interviewers were available to answer any questions regarding OC.

\section{RESULTS}

A total of 416 respondents participated in this study. The participants'demographic data are displayed in Table $\mathbf{1}$

Six participants (1.4\%) reported consuming alcohol. None of the participants reported using a pipe, cannabis, or tanbool (chewing tobacco). The participants' smoking habits are displayed in Table 2.

A total of 102 participants (24.5\%) stated that they were aware of OC. Fourteen participants (3.4\%) stated that they had been educated about $\mathrm{OC}$ by a health-care provider. Among the participants who were aware of OC, comparisons between demographic variables using the chi-square test and Fisher's exact test showed that hookah users and respondents with a family history of cancer and oral cancer exhibited significantly higher rates than other participants (Table 3). Gender, age, education level, family income, hospital type, history of 
systematic diseases, exposure to the sun, oral hygiene (brushing), use of cigarettes, electronic cigarettes, shammah, and qat were insignificant variables.

Participants who reported that they were aware of OC gave different correct answers to questions regarding OC (Table 4). When we summed their total correct answers to 16 items, 16 representing the highest level of knowledge, we found a mean score of $6.56 \pm 2.5$ with a midpoint of 8 .

Comparisons of the total knowledge score with different demographic variables and smoking habits using the t-test and ANOVA as parametric tests and the Mann-Whitney and Kruskal-Wallis tests as non-parametric tests, we found that non-smokers had a higher total knowledge score (mean: $6.7 \pm$ 2.5 ) than smokers (mean: $5 \pm 1.2 ; P=0.019$ ). All other factors (gender, age, education level, family income, hospital type, history of any systematic disease, exposure to the sun in the workplace, oral hygiene [brushing], family history of cancer, family history of oral cancer, and use of Hookah, electronic cigarettes, shammah, and qat) were insignificant.

Table 1. Participants' demographic data.

\begin{tabular}{|c|c|c|c|}
\hline Variable & Choices & $n$ & $\%$ \\
\hline \multirow{2}{*}{ Gender } & Male & 119 & $28.6 \%$ \\
\hline & Female & 297 & $71.4 \%$ \\
\hline \multirow{4}{*}{ Age } & 18-30 years & 240 & $57.7 \%$ \\
\hline & $31-40$ years & 80 & $19.2 \%$ \\
\hline & 41-60 years & 80 & $19.2 \%$ \\
\hline & 61 and above & 16 & $3.8 \%$ \\
\hline \multirow{3}{*}{ Education level } & High school or lower & 185 & $44.5 \%$ \\
\hline & College graduate & 215 & $51.7 \%$ \\
\hline & Post-graduate & 16 & $3.8 \%$ \\
\hline \multirow{2}{*}{ Hospital } & Governmental hospital & 169 & $40.6 \%$ \\
\hline & Private clinic & 247 & $59.4 \%$ \\
\hline \multirow{2}{*}{ Employment status } & Employed & 122 & $29.3 \%$ \\
\hline & Unemployed & 294 & $70.7 \%$ \\
\hline \multirow{2}{*}{ Exposure to the sun at the workplace } & Yes & 42 & $10.1 \%$ \\
\hline & No & 374 & $89.9 \%$ \\
\hline \multirow{3}{*}{ Medical history } & Nothing significant & 339 & $81.5 \%$ \\
\hline & One systemic disease & 55 & $13.2 \%$ \\
\hline & Two or more systemic diseases & 22 & $5.3 \%$ \\
\hline \multirow{2}{*}{ Family history of cancer } & Yes & 100 & $24.0 \%$ \\
\hline & No & 316 & $76.0 \%$ \\
\hline \multirow{2}{*}{ Family history of oral cancer } & Yes & 16 & $3.8 \%$ \\
\hline & No & 400 & $96.2 \%$ \\
\hline \multirow{4}{*}{ Oral hygiene (brushing frequency) } & Never & 25 & $6.0 \%$ \\
\hline & Once a day & 76 & $18.3 \%$ \\
\hline & Twice a day & 216 & $51.9 \%$ \\
\hline & More than twice a day & 98 & $23.6 \%$ \\
\hline \multirow{3}{*}{ Use of dental aids } & None & 162 & $38.9 \%$ \\
\hline & One & 207 & $49.8 \%$ \\
\hline & More than one & 47 & $11.3 \%$ \\
\hline
\end{tabular}

Table 2. Participants' smoking habits.

\begin{tabular}{|c|c|c|c|c|c|c|c|c|}
\hline \multirow{2}{*}{ Item } & \multicolumn{2}{|c|}{ Never } & \multicolumn{2}{c|}{ Once a week } & \multicolumn{2}{c|}{$\begin{array}{c}\mathbf{2 - 4} \\
\text { times a week }\end{array}$} & \multicolumn{2}{c|}{ Every day } \\
\cline { 2 - 9 } & $\boldsymbol{n}$ & $\mathbf{\%}$ & $\boldsymbol{n}$ & $\mathbf{\%}$ & $\boldsymbol{n}$ & $\mathbf{\%}$ & $\boldsymbol{n}$ & $\mathbf{\%}$ \\
\hline Cigarette & 378 & 90.9 & 4 & 1.0 & 3 & 0.7 & 31 & 7.5 \\
\hline Hookah (water pipe) & 373 & 89.7 & 24 & 5.8 & 9 & 2.2 & 10 & 2.4 \\
\hline Electronic cigarette & 413 & 99.3 & 0 & 0 & 0 & 0 & 3 & 0.7 \\
\hline Shammah (chewing tobacco) & 413 & 99.3 & 0 & 0 & 0 & 0 & 3 & 0.7 \\
\hline Qat (chewing tobacco) & 413 & 99.3 & 1 & 0.2 & 0 & 0 & 2 & 0.5 \\
\hline
\end{tabular}


Table 3. Relation of hookah use and family history of cancer and oral cancer to awareness of oral cancer.

\begin{tabular}{|c|c|c|c|c|}
\hline \multirow[t]{2}{*}{ Item } & \multirow[t]{2}{*}{ Choice } & \multicolumn{2}{|c|}{$\begin{array}{c}\text { Awareness of oral cancer } \\
\text { n (\%) }\end{array}$} & \multirow[t]{2}{*}{$P$} \\
\hline & & Yes & No & \\
\hline \multirow{2}{*}{ Family history of cancer } & Yes & $34(34.0 \%)$ & $66(66.0 \%)$ & \multirow{2}{*}{0.016} \\
\hline & No & $68(21.5 \%)$ & $248(78.5 \%)$ & \\
\hline \multirow{2}{*}{ Family history of oral cancer } & Yes & $11(68.8 \%)$ & $5(31.3 \%)$ & \multirow{2}{*}{$<0.001$} \\
\hline & No & $91(22.8 \%)$ & $309(77.3 \%)$ & \\
\hline \multirow{2}{*}{ Hookah use } & Yes & $17(37.8 \%)$ & $28(62.2 \%)$ & \multirow{2}{*}{0.042} \\
\hline & No & $85(22.9 \%)$ & $286(77.1 \%)$ & \\
\hline
\end{tabular}

Table 4. Correct answers to oral cancer questions of participants who were aware of oral cancer $(n=102)$.

\begin{tabular}{|c|c|c|}
\hline \multirow{2}{*}{ Items } & \multicolumn{2}{|c|}{ Correct answers } \\
\cline { 2 - 3 } & \multicolumn{2}{|c|}{$\boldsymbol{n}$} \\
\hline Oral cancer is not contagious. & 70 & 68.6 \\
\hline Oral cancer can be treated. & 80 & 78.4 \\
\hline Risk factor: smoking & 20 & 19.6 \\
\hline Risk factor: smokeless tobacco & 19 & 18.6 \\
\hline Risk factor: alcohol & 14 & 13.7 \\
\hline Risk factor: poor diet & 8 & 7.8 \\
\hline Risk factor: poor oral hygiene & 12 & 11.8 \\
\hline Risk factor: HPV infection & 7 & 6.9 \\
\hline Risk factor: sun exposure & 4 & 3.9 \\
\hline Risk factor: spicy food & 5 & 4.9 \\
\hline Risk factor: improper brushing and flossing technique & 77 & 75.5 \\
\hline Risk factor: sore denture & 46 & 45.1 \\
\hline Sign: difficulty chewing/swallowing & 57 & 55.9 \\
\hline Sign: mouth sore that does not heal & 77 & 75.5 \\
\hline Sign: abnormal lump in the mouth & 79 & 77.5 \\
\hline Sign: red/white patch & 54 & 52.9 \\
\hline
\end{tabular}

\section{DISCUSSION}

This study aimed to assess the general knowledge of OC among dental patients in Mecca, Saudi Arabia. Only 25\% of participants reported that they were aware of OC, which is alarmingly low. The level of knowledge about OC signs, symptoms, and risk factors among those who were aware of OC was also considerably low, as the total correct answers were lower than the midpoint. Most of those participants knew that $\mathrm{OC}$ is treatable and not contagious. The most recognizable risk factors were improper brushing and sore denture, while the least recognized factor was sun exposure. More than half of the participants with some knowledge were able to identify the four OC signs. Non-smokers had significantly better knowledge than smokers.

The level of general knowledge about $\mathrm{OC}$ is difficult to compare with previous studies, as they include multiple variables and elements not included in our study. We only analyzed the knowledge of participants who answered that they were aware of OC as a type of cancer. This is because it is not logical to take into account the answers of participants who are not aware of oral cancer.

The main risk factors for OC are alcohol, smokeless tobacco consumption and smoking $[5-7,30]$. In our study, the rates of participants who were aware of these risk factors were low (alcohol: 13.7\%; smoking: 19.6\%; smokeless tobacco: $18.6 \%$ ). These percentages are indeed lower than those reported in Sudan [24], Australia [12], Iran [17, 18], and Riyadh, Saudi Arabia [27, 28], which range from $33 \%$ to $79.4 \%$, from $65.2 \%$ to $95 \%$, and from $61.9 \%$ to $84 \%$ for alcohol, smoking, and smokeless tobacco, respectively. The reason for this might be that our participants assumed that these risk factors are only concerned with lung or esophagus cancer. In fact, some participants explicitly stated this. However, this explanation cannot be supported by our data, and further investigations are needed.

In our study, sun exposure was one of the least identified risk factors for OC, as also reported by other studies [27, 28]. The most identifiable risk factor, on the other hand, was improper brushing and flossing technique which was found to be significantly related to oral cancer by a study conducted in Taiwan [31]. However, it is unclear why even though participants identified this risk factor, most failed to identify poor oral hygiene. This might be related to the influence of commercials on mass media, which emphasize the importance of tooth brushing rather than the main objective, which is to refrain from poor oral hygiene practices. However, a 
qualitative study might be needed to confirm this hypothesis.

Regarding the signs and symptoms of OC, $55.9 \%$ of our participants identified difficulty chewing or swallowing (dysphagia), 75.5\% identified unhealed mouth sores, $77.5 \%$ identified abnormal lumps in the mouth, and $52.9 \%$ identified red or white patches. In comparison, only a study in Sudan showed similar levels of knowledge regarding dysphagia [24]. Studies in Riyadh found lower levels of knowledge regarding mouth soreness $(30 \%)$, lumps $(41.1 \%)$, and red patches $(26.1 \%)$ or white patches $(25.9 \%)[27,28]$. This might be because we only analyzed the answers of the participants who were aware of OC, whereas other studies have taken into account all the participants' answers.

It is noteworthy that in our study, whereas the rates of correct answers to questions related to risk factors (except sore denture and improper brushing and flossing technique) are low, the rates of correct answers concerning signs and symptoms are high. This again might be related to the fact that we only asked participants who were aware of OC, who might be more likely to be familiar with cancer or oral cancer patients and thus more visually familiar with some symptoms. On the other hand, recognizing risk factors such as sun exposure requires more abstract knowledge.

As previously noted, only $25 \%$ of the participants reported that they were aware of OC. However, even their knowledge was poor. This suggests that even people who think they are aware of OC might lack basic knowledge. It might, therefore, be beneficial to target even those people with health education campaigns to reinforce or correct their knowledge about OC risk factors, signs, and symptoms. Moreover, we found no significant differences between most demographic variables and health-related habits. This also indicates that health promotion campaigns should not target specific groups but a broad spectrum of the population. Furthermore, in our study, only $14(3.4 \%)$ of the participants stated that they had been educated about $\mathrm{OC}$ by a health-care provider. This rate, which is considerably lower than those reported in studies conducted in the USA (40\%) [19], Iran (26\%) [17], and Riyadh (30\%) [27], suggests that the efforts of health-care providers and educational health programs in Mecca are inadequate, and more efforts are required.

This was the first study to assess the knowledge of OC among dental patients in Mecca, Saudi Arabia, which includes many nationalities and receives millions of Muslims every year for the Hajj and Umrah pilgrimages [25, 26]. Our assessment can be beneficial for a city that receives this great number and diversity of people every year. It should be noted, however, that this study used a convenience sample, which renders it susceptible to bias and makes the results difficult to generalize on the entire country. Moreover, as we only analyzed participants who reported that they had previous knowledge of OC, our data might overestimate the knowledge of OC among patients in Mecca.

\section{CONCLUSION}

This study suggests low levels of knowledge about OC and its risk factors, signs, and symptoms among dental patients in Mecca. Therefore, health education programs should be initiated to improve the community's knowledge regarding this disease.

\section{ETHICS APPROVAL AND CONSENT TO PARTICIPATE}

This study obtained approval from the Institutional Review Board of the Faculty of Dentistry of Umm Al-Qura University, Saudi Arabia. (No. 113-18).

\section{HUMAN AND ANIMAL RIGHTS}

No animals were used in this research. All research procedures on humans followed the ethical standards of the committees responsible for human experimentation (institutional and national) and the Helsinki Declaration of 1975, as revised in 2013 (http://ethics.iit.edu/ecodes/node/ 3931).

\section{CONSENT FOR PUBLICATION}

All patients signed informed consent forms prior to participating in this study.

\section{AVAILABILITY OF DATA AND MATERIALS}

The authors confirm that the data supporting the findings of this study are available within the article.

\section{FUNDING}

None.

\section{CONFLICT OF INTEREST}

The authors declare no conflict of interest, financial or otherwise.

\section{ACKNOWLEDGEMENTS}

Declared none.

\section{REFERENCES}

[1] Thomson P, Ed. Oral precancer: diagnosis and management of potentially malignant disorders. Newcastle upon Tyne, UK: WileyBlackwell 2012.

[http://dx.doi.org/10.1002/9781118702840]

[2] Ferlay J, Shin HR, Bray F, Forman D, Mathers C, Parkin DM Estimates of worldwide burden of cancer in 2008: GLOBOCAN 2008. Int J Cancer 2010; 127(12): 2893-917.

[http://dx.doi.org/10.1002/ijc.25516] [PMID: 21351269]

[3] World Health Organization. Standardization of reporting of dental diseases and condition: report of an Expert Committee on Dental Association.

[4] Scully C, Bagan J. Oral squamous cell carcinoma: overview of current understanding of aetiopathogenesis and clinical implications. Oral Dis 2009; 15(6): 388-99.

[http://dx.doi.org/10.1111/j.1601-0825.2009.01563.x] [PMID: 19371401]

[5] La Vecchia C, Tavani A, Franceschi S, Levi F, Corrao G, Negri E. Epidemiology and prevention of oral cancer. Oral Oncol 1997; 33(5): 302-12.

[http://dx.doi.org/10.1016/S1368-8375(97)00029-8] [PMID: 9415327]

[6] Thomas SJ, Bain CJ, Battistutta D, Ness AR, Paissat D, Maclennan R. Betel quid not containing tobacco and oral cancer: a report on a casecontrol study in Papua New Guinea and a meta-analysis of current evidence. Int J Cancer 2007; 120(6): 1318-23.

[http://dx.doi.org/10.1002/ijc.22304] [PMID: 17163423]

[7] Song H, Wan Y, Xu YY. Betel quid chewing without tobacco: a metaanalysis of carcinogenic and precarcinogenic effects. Asia Pac J Public 
Health 2015; 27(2): NP47-57.

[http://dx.doi.org/10.1177/1010539513486921] [PMID: 23666841]

[8] Jeng JH, Chang MC, Hahn LJ. Role of areca nut in betel quidassociated chemical carcinogenesis: current awareness and future perspectives. Oral Oncol 2001; 37(6): 477-92.

[http://dx.doi.org/10.1016/S1368-8375(01)00003-3] [PMID: 11435174]

[9] Hashibe M, Mathew B, Kuruvilla B, et al. Chewing tobacco, alcohol, and the risk of erythroplakia. Cancer Epidemiol Biomarkers Prev 2000; 9(7): 639-45. [PMID: 10919731]

[10] Silverman S Jr, Kerr AR, Epstein JB. Oral and pharyngeal cancer control and early detection. J Cancer Educ 2010; 25(3): 279-81. [Internet].

[http://dx.doi.org/10.1007/s13187-010-0045-6] [PMID: 20204575]

[11] Scully C, Felix DH. Oral medicine--update for the dental practitioner oral cancer. Br Dent J 2006; 200(1): 13-7.

[http://dx.doi.org/10.1038/sj.bdj.4813117] [PMID: 16415822]

[12] Formosa J, Jenner R, Nguyen-Thi MD, Stephens C, Wilson C, Ariyawardana A. Awareness and knowledge of oral cancer and potentially malignant oral disorders among dental patients in far North Queensland, Australia. Asian Pac J Cancer Prev 2015; 16(10): 4429-34.

[http://dx.doi.org/10.7314/APJCP.2015.16.10.4429] [PMID: 26028109]

[13] Chandu A, Smith ACH, Rogers SN. Health-related quality of life in oral cancer: a review. J Oral Maxillofac Surg 2006; 64(3): 495-502. [http://dx.doi.org/10.1016/j.joms.2005.11.028] [PMID: 16487814]

[14] Dolan RW, Vaughan CW, Fuleihan N. Symptoms in early head and neck cancer: an inadequate indicator. Otolaryngol Head Neck Surg 1998; 119(5): 463-7.

[http://dx.doi.org/10.1016/S0194-5998(98)70102-0] [PMID: 9807070]

[15] Kowalski LP, Franco EL, Torloni H, et al. Lateness of diagnosis of oral and oropharyngeal carcinoma: factors related to the tumour, the patient and health professionals. Eur J Cancer B Oral Oncol 1994; 30B(3): 167-73.

[http://dx.doi.org/10.1016/0964-1955(94)90086-8] [PMID: 7920162]

[16] Scott SE, McGurk M, Grunfeld EA. The process of symptom appraisal: cognitive and emotional responses to detecting potentially malignant oral symptoms. J Psychosom Res 2007; 62(6): 621-30.

[http://dx.doi.org/10.1016/j.jpsychores.2006.12.020] [PMID: 17540219]

[17] Razavi SM, Tahani B, Nouri S, et al. Oral cancer knowledge and practice among dental patients and their attitude towards tobacco cessation in Iran. 2015; 16: pp. 5439-44.

[http://dx.doi.org/10.7314/APJCP.2015.16.13.5439]

[18] Awojobi O, Scott SE, Newton T. Patients' perceptions of oral cancer screening in dental practice: a cross-sectional study. BMC Oral Health 2012; 12 (1): 55 .

[http://dx.doi.org/10.1186/1472-6831-12-55] [PMID: 23249393]

[19] Shimpi N, Jethwani M, Bharatkumar A, Chyou PH, Glurich I, Acharya

A. Patient awareness/knowledge towards oral cancer: A cross- sectional survey. BMC Oral Health 2018; 18(1): 86. [http://dx.doi.org/10.1186/s12903-018-0539-x] [PMID: 29764414]

[20] Rai A, Kumar A, Abraham L, et al. Self awareness of oral potentially malignant disorders and oral cancer among high-risk patients. International Journal of Cancer Management 2017; 10(8) [http://dx.doi.org/10.5812/ijcm.5973]

[21] Hassona Y, Scully C, Almangush A, Baqain Z, Sawair F. Oral potentially malignant disorders among dental patients: a pilot study in Jordan. Asian Pac J Cancer Prev 2014; 15(23): 10427-31. [http://dx.doi.org/10.7314/APJCP.2014.15.23.10427] 25556487]

[22] Hassona Y, Scully C, Abu Ghosh M, Khoury Z, Jarrar S, Sawair F. Mouth cancer awareness and beliefs among dental patients. Int Dent $\mathrm{J}$ 2015; 65(1): 15-21.

[http://dx.doi.org/10.1111/idj.12140] [PMID: 25371164]

[23] Joseph BK, Ali MA, Sundaram DB. Awareness of mouth cancer among adult dental patients attending the Kuwait university dental school clinic. J Cancer Educ 2018; 33(2): 340-5.

[http://dx.doi.org/10.1007/s13187-016-1110-6] [PMID: 27631717]

[24] Babiker TM, Osman KA, Mohamed SA, Mohamed MA, Almahdi HM. Oral cancer awareness among dental patients in Omdurman, Sudan: a cross-sectional study. BMC Oral Health 2017; 17(1): 69. [http://dx.doi.org/10.1186/s12903-017-0351-z] [PMID: 28335762]

[25] Al-Haqwi AI, Tamim H, Asery A. Knowledge, attitude and practice of tobacco smoking by medical students in Riyadh, Saudi Arabia. Ann Thorac Med 2010; 5(3): 145-8.

[http://dx.doi.org/10.4103/1817-1737.65044] [PMID: 20835308]

[26] Kujan O, Alzoghaibi I, Azzeghaiby S, et al. Knowledge and attitudes of Saudi dental undergraduates on oral cancer. J Cancer Educ 2014; 29(4): 735-8. [Internet].

[http://dx.doi.org/10.1007/s13187-014-0647-5] [PMID: 24699922]

[27] Al-Maweri SA, Al-Soneidar WA, Dhaifullah E, Halboub ES, Tarakji B. Oral cancer: awareness and knowledge among dental patients in Riyadh. J Cancer Educ 2017; 32(2): 308-13.

[http://dx.doi.org/10.1007/s13187-015-0924-y] [PMID: 26423059]

[28] Al-Maweri SA, Tarakji B, Alsalhani AB, et al. Oral cancer awareness of the general public in Saudi Arabia. Asian Pac J Cancer Prev 2015; 16(8): 3377-81.

[http://dx.doi.org/10.7314/APJCP.2015.16.8.3377] [PMID: 25921148]

[29] Oral Cancer Examination [Internet]. Ontario Dental Hygienists' Association (ODHA) 2020. Available from: https://odha.on.ca/your-oral-health/oral-cancer-examination/

[30] Khurshid Z, Zafar MS, Khan RS, Najeeb S, Slowey PD, Rehman IU. Role of Salivary Biomarkers in Oral Cancer Detection. Adv Clin Chem 2018; 86: 23-70.

[http://dx.doi.org/10.1016/bs.acc.2018.05.002] [PMID: 30144841]

[31] Chang JS, Lo HI, Wong TY, et al. Investigating the association between oral hygiene and head and neck cancer. Oral Oncol 2013; 49(10): 1010-7.

[http://dx.doi.org/10.1016/j.oraloncology.2013.07.004] [PMID: 23948049]

This is an open access article distributed under the terms of the Creative Commons Attribution 4.0 International Public License (CC-BY 4.0), a copy of which is available at: (https://creativecommons.org/licenses/by/4.0/legalcode). This license permits unrestricted use, distribution, and reproduction in any medium, provided the original author and source are credited. 